\title{
Filter paper collection of Plasmodium falciparum mRNA for detecting low-density gametocytes
}

\author{
Sophie Jones ${ }^{1}$, Colin J Sutherland ${ }^{1}$, Cornelus Hermsen², Theo Arens², Karina Teelen², Rachel Hallett ${ }^{1}$, \\ Patrick Corran ${ }^{1}$, Marga van der Vegte-Bolmer ${ }^{2}$, Robert Sauerwein ${ }^{2}$, Chris J Drakeley ${ }^{1}$ and Teun Bousema ${ }^{1,2^{*}}$
}

\begin{abstract}
Background: Accurate sampling of sub-microscopic gametocytes is necessary for epidemiological studies to identify the infectious reservoir of Plasmodium falciparum. Detection of gametocyte mRNA achieves sensitive detection, but requires careful handling of samples. Filter papers can be used for collecting RNA samples, but rigorous testing of their capacity to withstand adverse storage conditions has not been fully explored.
\end{abstract}

Methods: Three gametocyte dilutions: 10/ $\mathrm{LL}, 1.0 / \mu \mathrm{L}$ and $0.1 / \mu \mathrm{L}$ were spotted onto Whatman ${ }^{\mathrm{TM}} 903$ Protein Saver Cards, FTA Classic Cards and 3MM filter papers that were stored under frozen, cold chain or tropical conditions for up to 13 weeks. RNA was extracted, then detected by quantitative nucleic acid sequence-based amplification (QT-NASBA) and reverse-transcriptase PCR (RT-PCR).

Results: Successful gametocyte detection was more frequently observed from the Whatman 903 Protein Saver Card compared to the Whatman FTA Classic Card, by both techniques $(p<0.0001)$. When papers were stored at higher temperatures, a loss in sensitivity was experienced for the FTA Classic Card but not the 903 Protein Saver Card or Whatman $3 \mathrm{MM}$ filter paper. The sensitivity of gametocyte detection was decreased when papers were stored at high humidity.

Conclusions: This study indicates the Whatman 903 Protein Saver Card is better for Pfs 25 mRNA sampling compared to the Whatman FTA Classic Card, and that the Whatman 3MM filter paper may prove to be a satisfactory cheaper option for Pfs 25 mRNA sampling. When appropriately dried, filter papers provide a useful approach to Pfs 25 mRNA sampling, especially in settings where storage in RNA-protecting buffer is not possible.

Keywords: Reverse-transcription polymerase chain reaction (RT-PCR), Quantitative nucleic acid sequence-based amplification (QT-NASBA), Sub-microscopic, Gametocyte, Detection, Elimination, Transmission, Ribonucleic acid (RNA), Filter paper

\section{Background}

The recent decline in the burden of malaria has placed malaria elimination and eradication back on the agenda of the international research community and health policy makers [1-4]. As a consequence, vaccines and antimalarial drugs that specifically target the transmission stages of malaria parasites, gametocytes, are a high priority $[1,2]$. These interventions aim to reduce the infectious reservoir of malaria: the number of individuals capable of infecting mosquitoes. Infectiousness of humans

\footnotetext{
* Correspondence: teun.bousema@lshtm.ac.uk

'Department of Immunology \& Infection; Faculty of Infectious and Tropical Diseases, London School of Hygiene and Tropical Medicine, London, UK ${ }^{2}$ Department of Medical Microbiology, Radboud University Nijmegen Medical Centre, Nijmegen, The Netherlands
} tocytes in the peripheral blood, and sensitive detection of gametocytes is therefore paramount. In the last decade, it has become evident that detection of gametocytes by microscopy is insufficiently sensitive to assess potential infectivity. Gametocyte densities below the microscopic threshold for gametocyte detection $(\sim 5$ gametocytes $/ \mu \mathrm{L})$ frequently result in mosquito infection [5-8]. Molecular detection of low levels of gametocyte specific mRNA enables identification of submicroscopic gametocyte carriers, and has revealed gametocyte prevalence to be four to ten times higher than estimated by microscopy [9-20].

However, whilst mRNA-based gametocyte detection has aided epidemiological research concerned with low 
density Plasmodium falciparum gametocytes, the labile nature of RNA and the ubiquitous presence of RNAses pose challenges to sampling under field conditions, where high heat and humidity may lead to mRNA degradation [21]. Optimal handling of RNA samples, eg, stabilizing in buffer, shipping on dry ice, and storing at $-80^{\circ} \mathrm{C}$, allows maintenance of integrity of nucleic acids but restricts sampling to well-equipped laboratories. To facilitate RNA sampling and storage in settings with limited resources a filter paper-based approach has been proposed [22]. Filter papers have been routinely used for reliable collection and storage of whole blood samples for both antibody and DNA recovery [23,24]. The value of filter-paper matrices for malaria mRNA collection remains to be confirmed, in particular for detecting lowdensity infections under field conditions. In this study, the suitability of three different filter papers that are recommended for DNA or RNA storage has been determined for the mRNA-based detection of low-density gametocyte concentrations. Samples were stored on two filter papers under different conditions, ranging from those available in well-equipped laboratories to humid and hot tropical conditions, whereas the third paper was included in a smaller subset of conditions Two commonly used RNA extraction protocols were compared and gametocytes were detected by both reverse-transcriptase PCR (RT-PCR) and quantitative nucleic acid sequence based amplification (QT-NASBA).

\section{Methods}

Figure 1 depicts an overview of the methodology. Plasmodium falciparum gametocytes were cultured as previously described $[25,26]$, quantified in counting chambers by two independent microscopists and diluted to densities of 10, 1.0 and 0.1 gametocytes per $\mu \mathrm{L}$ in parasite negative European whole blood. These concentrations were chosen because they span the microscopic threshold for gametocyte detection [27] but may still be detectable by molecular methods [28]. Large blood spots of fifty $\mu \mathrm{L}$ of the different dilutions were aliquoted in five replicates per filter paper, incubation condition and time point, and allowed to dry overnight before being sealed into plastic bags with a silica desiccant sachet. To evaluate the impact of sub-optimal drying on mRNA recovery, after aliquoting the sample some papers were immediately sealed into bags without air drying overnight, and were stored without desiccant in containers with $~ 80 \%$ relative humidity. Two sets of papers were handled this way and are referred to as the conditions 'with humidity' in Figure 1.

Three filter paper types were evaluated: the Whatman 903 Protein Saver Card, Whatman FTA Classic Card and the Whatman 3MM filter paper (GE Healthcare Ltd., New Jersey, USA). The FTA Classic Card was included as it is impregnated with chemicals that lyse cells, denature proteins and protect nucleic acids from nucleases, oxidative and UV damage. The 903 Protein Saver Card, has no stabilizing properties but has previously been shown to be suitable for RNA collection [22,29]. The 3MM plain filter paper has no nucleic acid stabilizing properties, was not expected to perform well and was therefore evaluated under a smaller subset of conditions [30]. Storage conditions were considered to replicate likely conditions that may be encountered at field sites for sampling and during transportation back to the laboratory. Frozen and cold chain incubation temperatures were: $-80^{\circ} \mathrm{C},-20^{\circ} \mathrm{C}$ and $4^{\circ} \mathrm{C}$. To represent laboratories without access to any cold storage, ambient/room temperature (an average of $22^{\circ} \mathrm{C}$, but with a range from $20-24^{\circ} \mathrm{C}$ ) and hot tropical temperatures $\left(35^{\circ} \mathrm{C}\right.$, in an incubator) conditions were included. To mimic sampling under humid conditions, papers were also stored at $22^{\circ} \mathrm{C}$ and at $35^{\circ} \mathrm{C}$ in a wet box with a hygrometer, reaching $\sim 80 \%$ relative humidity. Filter papers were incubated for one week under a 'transportation/shipping' temperature, then moved to a second 'storage' temperature, where replicates were kept for an additional four weeks or twelve weeks before RNA extraction.

As non- filter paper controls, $50 \mu \mathrm{L}$ aliquots of the three gametocyte densities and parasite negative diluent blood were stored in RNA stabilizing guanidine isothiocyanate buffer [31], at $-80^{\circ} \mathrm{C}$. A total of twenty replicates of gametocyte negative human blood was blotted onto 903 Protein Saver Cards; twenty onto the FTA Classic Card and ten onto the $3 \mathrm{MM}$ papers. These negative controls were stored at $-20^{\circ} \mathrm{C}$ or $35^{\circ} \mathrm{C}$ with silica gel desiccant before extraction and analysis.

\section{RNA extraction}

To determine optimum extraction methods, a smallscale comparison extracting total RNA with the RNeasy Mini Blood kit (QIAGEN Ltd, Crawley, UK) and a guanidine based extraction protocol $[22,31]$ was conducted. Replicates of all three gametocyte densities were spotted onto the 903 Protein Saver Card $(n=21)$ and the FTA Classic Card $(\mathrm{n}=21)$ which were air dried overnight then stored at $-80^{\circ} \mathrm{C}$ or $-20^{\circ} \mathrm{C}$ for twenty-four hours. RNA was extracted by both methods and sensitivity was determined by QT-NASBA, and measured in terms of the number of positive results. RNeasy extraction from filter papers was performed as described elsewhere, following an initial homogenization step where entire $50 \mu \mathrm{L}$ blood spots were excised from filter papers then rocked horizontally in individual eppendorfs at $150 \mathrm{rpm}$ for one hour with $500 \mu \mathrm{L}$ of RNeasy Lysis Buffer (QIAGEN Ltd, Crawley, UK) plus $\beta$-mercaptoethanol $(0.14 \mathrm{M}$ final concentration). Following this, samples were centrifuged 


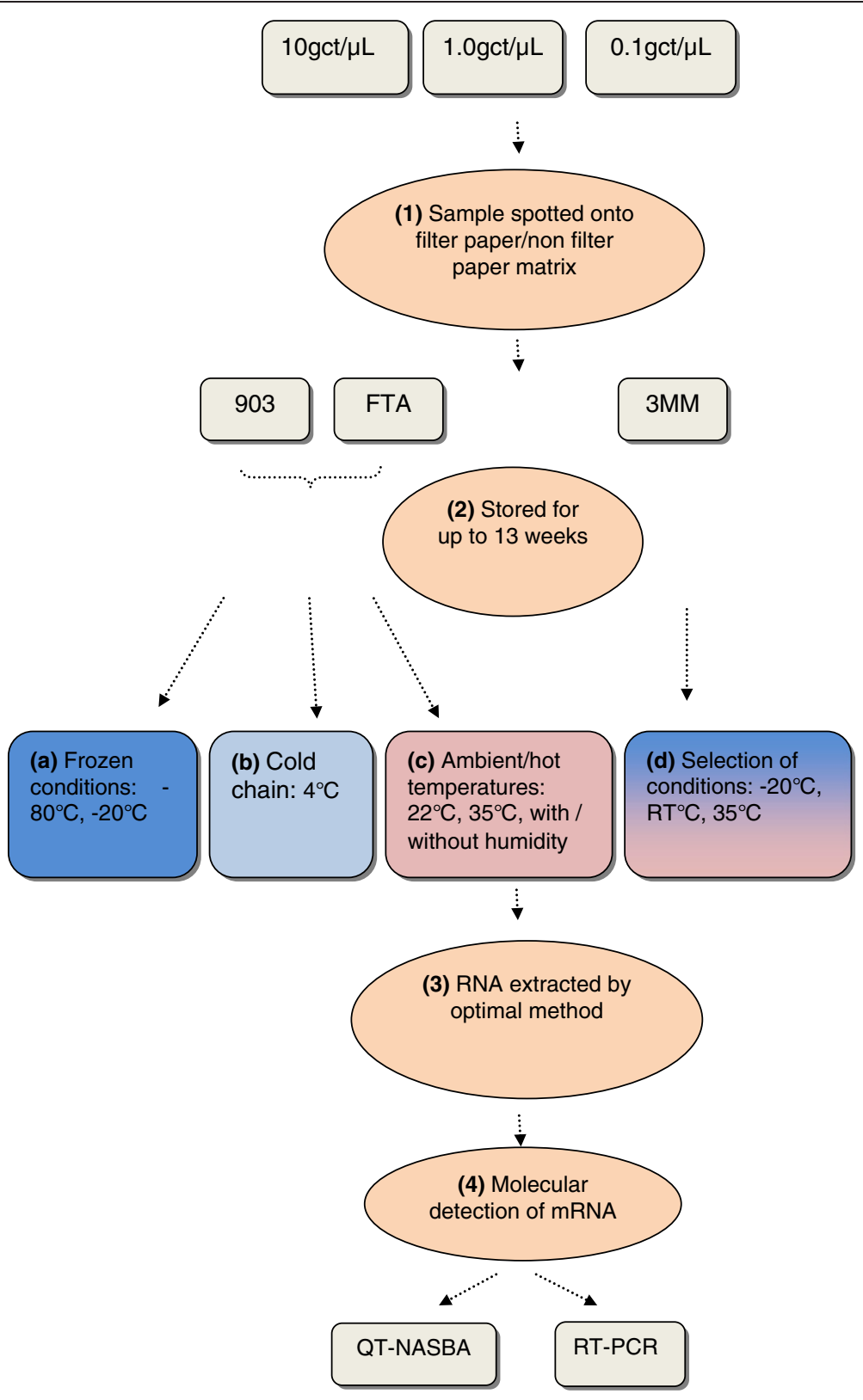

Figure 1 Overview of experimental procedure.

through QIAshredder columns (QIAGEN Ltd, Crawley, UK) as described elsewhere [22].

For guanidine-based extraction, filter papers were similarly homogenized in $700 \mu \mathrm{L}$ of guanidine isothiocyanate L6 buffer (8.3 M GuSCN, $82 \mathrm{mM}$ Tris- $\mathrm{HCl}$ pH 6.4, $36 \mathrm{mMM}$ EDTA pH 8 and $2 \%$ Triton-X-100) and rocked for 1.5 hours at $150 \mathrm{rpm}$. After this, the supernatant was kept and an additional $700 \mu \mathrm{L}$ of guanidine isothiocyanate L6 buffer was added to the filter paper that was rocked for thirty more minutes at $150 \mathrm{rpm}$. Then the supernatants were pooled and RNA extraction performed as described [31]. Non filter paper controls were gametocyte concentrations of $10,1.0$ and 0.1 gametocytes per $\mu \mathrm{L}$ in parasite negative European whole blood that was stored immediately in L6 buffer, and were extracted according to protocol from this media [31].

\section{Gametocyte detection}

Gametocyte specific Pfs25 mRNA transcripts were detected in extracted material using quantitative nucleic acid sequence based amplification (QT-NASBA) and reverse transcription polymerase chain reaction (RT-PCR). QT-NASBA was conducted as previously described using the NucliSENS Easy Q Basic Kit, Version 2 (BioMérieux 
Benelux B.V, Boxtel, The Netherlands), see Table S1 in the additional files. for primers and molecular beacon [32]. Prior to RT-PCR, potentially contaminating DNA was digested with DNA-free ${ }^{\mathrm{TM}}$ (Applied Biosystems, Warrington, UK). Twenty $\mu \mathrm{L}$ reactions were conducted according to the manufacturer's protocol with the following amendments: RNA sample was added to $2 \mu \mathrm{L}$ of rDNase I, $2 \mu \mathrm{L}$ of $10 \mathrm{X}$ DNase I buffer, and inactivated with $4 \mu \mathrm{L}$ of DNase inactivation reagent. Nested RTPCR was conducted using a previously published protocol with novel primers, described in Table S1 in the additional files and ammended cycling conditions [22,33]. Reactions were set up using lyophilized Illustra Ready to Go RT-PCR beads (Illustra, GE Healthcare UK Ltd, Buckinghamshire, UK) and PCR cycling was conducted as described below. To generate cDNA, reactions were held at $42^{\circ} \mathrm{C}$ for 30 minutes, followed by $95^{\circ} \mathrm{C}$ for five minutes. Primary PCR conditions were $94^{\circ} \mathrm{C}$ for two minutes, then 45 cycles of: $94^{\circ} \mathrm{C}$ for thirty seconds, $52^{\circ} \mathrm{C}$ for one minute and $68^{\circ} \mathrm{C}$ for 2.5 minutes.. Nested PCR was performed using two $\mu \mathrm{L}$ of primary PCR product and the same conditions as before, but with thirty cycles instead. The PCR product was analysed on a $1.5 \%$ agarose gel and produced a band of $\sim 124$ base pairs.

\section{Data analysis}

Statistical comparisons of the filter paper types and detection methods were performed using statistical software STATA Version 11 (Statacorp, Texas, USA). Comparisons of filter paper or extraction performance were done by Pearson's $x^{2}$ or trend test. Where appropriate, multivariate logistic regression models were used to allow for the effect of gametocyte concentrations when comparing the effect of storage temperature by filter paper type and to allow for the effects of gametocyte concentrations and storage temperature when comparing the performance of filter papers. GraphPadPrism Version 5 (GraphPad Software Inc., La Jolla, USA) was used for graphical presentation.

\section{Results}

\section{Selection of an RNA extraction method}

In a pilot experiment RNA extraction from bloodspots on desiccated 903 Protein Saver Cards stored at $-80^{\circ} \mathrm{C}$ or $-20^{\circ} \mathrm{C}$ was found to be similar using guanidine-based extraction (18/21 successful amplifications) or RNeasy based extraction (19/21 successful amplifications), with no significant difference found between the two $(\mathrm{p}=0.635)$, Table 1 RNA extraction from the FTA Classic Card was less efficient by RNeasy (12/21 successful amplifications) compared to guanidine-based extraction (17/21 successful amplifications), although this difference was not significant $(p=0.095)$, Table 1 . Therefore, all subsequent experiments were continued with guanidine-based extraction, which is less laborious and less expensive.

\section{Positive and negative controls}

For non-filter paper controls when gametocyte dilutions were stored at $-80^{\circ} \mathrm{C}$ in protective guanidine buffer, all of the samples with 10 gametocytes $/ \mu \mathrm{L}$ or one gametocyte $/ \mu \mathrm{L}$ were detected by QT-NASBA, but six out of eight were detected for both dilutions by RT-PCR. For the 0.1 gametocytes/ $\mu \mathrm{L}$ samples five of eight were successfully detected by QT-NASBA, and three of eight for RT-PCR (Table 2). None of the negative European donor blood showed RNA amplification by either QT-NASBA or RT-PCR (0/23).

\section{Storage duration}

There was no evidence for a difference in the proportion of successful amplifications between samples stored in their second condition for four weeks compared to those stored for 12 weeks by either QT-NASBA (regression analysis adjusting for gametocyte concentration and storage condition, $\mathrm{p}=0.89$ ) or RT-PCR (regression analysis adjusting for gametocyte concentration and storage condition, $\mathrm{p}=0.49$ ) (Tables $\mathrm{S} 2$ and $\mathrm{S} 3$ in the additional files). Therefore, data from the two time-points was combined for the comparison of storage conditions for subsequent analysis.

\section{Detection of gametocytes from filter papers Detection of gametocytes from filter papers stored at $-80^{\circ} \mathrm{C}$ or $-20^{\circ} \mathrm{C}$}

All gametocyte concentrations that were blotted onto the 903 Protein Saver Cards and stored with desiccant at $-80^{\circ} \mathrm{C}$ were successfully detected by QT-NASBA and RT-PCR (Figure 2a, Tables S2 and S3 in the additional files). All gametocyte concentrations that were blotted onto the FTA Classic Cards and stored with desiccant at

Table 1 RNeasy Mini Blood kit (QIAGEN Ltd, Crawley, UK) and Boom RNA extraction technique comparison, determined by QT-NASBA

\begin{tabular}{|c|c|c|c|c|c|c|c|c|c|c|c|c|}
\hline & \multicolumn{3}{|c|}{$-80^{\circ} \mathrm{C}$} & \multicolumn{3}{|c|}{$-20^{\circ} \mathrm{C}$} & \multicolumn{3}{|c|}{$-80^{\circ} \mathrm{C}$} & \multicolumn{3}{|c|}{$-20^{\circ} \mathrm{C}$} \\
\hline & \multicolumn{6}{|c|}{903 protein saver } & \multicolumn{6}{|c|}{ FTA TM Classic Card } \\
\hline Extraction type & 10 & 1 & 0.1 & 10 & 1 & 0.1 & 10 & 1 & 0.1 & 10 & 1 & 0.1 \\
\hline Boom & $(5 / 5)$ & $(5 / 5)$ & $(4 / 5)$ & $(2 / 2)$ & $(1 / 2)$ & $(1 / 2)$ & $(5 / 5)$ & $(5 / 5)$ & $(1 / 5)$ & $(2 / 2)$ & $(2 / 2)$ & $(2 / 2)$ \\
\hline RNeasy & $(5 / 5)$ & $(5 / 5)$ & $(4 / 5)$ & $(2 / 2)$ & $(2 / 2)$ & $(1 / 2)$ & $(5 / 5)$ & $(3 / 5)$ & $(1 / 5)$ & $(2 / 2)$ & $(1 / 2)$ & $(0 / 2)$ \\
\hline
\end{tabular}


Table 2 Detection comparison for QT-NASBA and RT-PCR for whole blood stored directly in guanidine RNA preservation buffer at $-80^{\circ} \mathrm{C}$

\begin{tabular}{lllll}
\hline & \multicolumn{4}{l}{ Gametocyte density/ $\boldsymbol{\mu l}$} \\
\cline { 2 - 5 } & $\mathbf{1 0}$ & $\mathbf{1}$ & $\mathbf{0 . 1}$ & negative \\
\hline QT NASBA & $100(8 / 8)$ & $100(8 / 8)$ & $62.5(5 / 8)$ & $0(0 / 4)$ \\
RT-PCR & $75(6 / 8)$ & $75(6 / 8)$ & $37.5(3 / 8)$ & $0(0 / 4)$ \\
\hline
\end{tabular}

$-80^{\circ} \mathrm{C}$ were successfully detected by QT-NASBA but not by RT-PCR (Figure 2a, p=0.007).

Detection of gametocytes from filter papers stored at increasing temperatures The proportion of cards that gave successful amplification for all gametocyte dilutions was unaffected by increasing storage temperature if using the 903 Protein Saver Card (Figures 3-4, Tables S2 and S3 in the additional files; (test for trend adjusting for gametocyte concentration, $\mathrm{p}=0.18$ ).

In contrast, there was evident loss in sensitivity when samples on FTA Classic Cards were stored at a higher temperature. Successful detection by QT-NASBA of gametocytes blotted on FTA Classic Cards was achieved for $100 \%$ (9/9), $63.2 \%$ (12/19), $53.3 \%(16 / 30)$ and $31.6 \%$ $(6 / 19)$ of the samples that were continuously stored with desiccant at $-80^{\circ} \mathrm{C},-20^{\circ} \mathrm{C}, 22^{\circ} \mathrm{C}$ and $35^{\circ} \mathrm{C}$, respectively (test for trend, $\mathrm{p}=0.002$ ). Similarly, successful detection by RT-PCR of gametocytes blotted on FTA Classic Cards was achieved for $46.7 \%$ (7/15), $50.0 \%$ (5/10), $27.8 \%(5 / 18)$ and $10.5 \%(2 / 19)$ of the samples that were continuously stored with desiccant at $-80^{\circ} \mathrm{C},-20^{\circ} \mathrm{C}, 22^{\circ} \mathrm{C}$ and $35^{\circ} \mathrm{C}$, respectively (test for trend adjusting for gametocyte concentration, $\mathrm{p}=0.02$ ).
The use of RT-PCR for gametocyte detection led to similar conclusions about the effect of increasing storage temperature on the detectability of gametocytes from 903 Protein Saver Cards (test for trend adjusting for gametocyte concentration, $\mathrm{p}=0.83$ ) or FTA Classic Cards (test for trend adjusting for gametocyte concentration, $\mathrm{p}=0.01$ ).

\section{Detection of gametocytes from filter papers stored at changing temperatures}

Compared to 903 Protein Saver Cards that were continuously stored at $-20^{\circ} \mathrm{C}$, the chance of detecting gametocytes by QT-NASBA from 903 Protein Saver Cards that were first stored at higher temperatures $\left(4^{\circ} \mathrm{C}, 22^{\circ} \mathrm{C}\right.$ or $\left.35^{\circ} \mathrm{C}\right)$ was not reduced (test for trend, $\mathrm{p}=0.41$ ). In contrast, FTA Classic Cards that were first stored at higher temperatures $\left(4^{\circ} \mathrm{C}\right.$, $22^{\circ} \mathrm{C}$ or $35^{\circ} \mathrm{C}$ ) were less frequently successfully amplified by QT-NASBA (test for trend adjusting for gametocyte concentration, $p=0.09$ ). The use of RT-PCR for gametocyte detection resulted in similar conclusions about changing storage temperature and a loss in the detectability of gametocytes from 903 Protein Saver Cards (test for trend adjusting for gametocyte concentration, $\mathrm{p}=1.00$ ) and FTA Classic Cards (test for trend adjusting for gametocyte concentration, $\mathrm{p}=0.09$ ).

\section{Detection of gametocytes from filter papers stored under humid conditions}

A subset of filter papers were examined in humid and dry conditions; these samples were stored at $22^{\circ} \mathrm{C}$ for one week and subsequently shifted to $-20^{\circ} \mathrm{C}$ (Figure 3) or were stored at $35^{\circ} \mathrm{C}$ for an additional 12 weeks (Figure 4). For

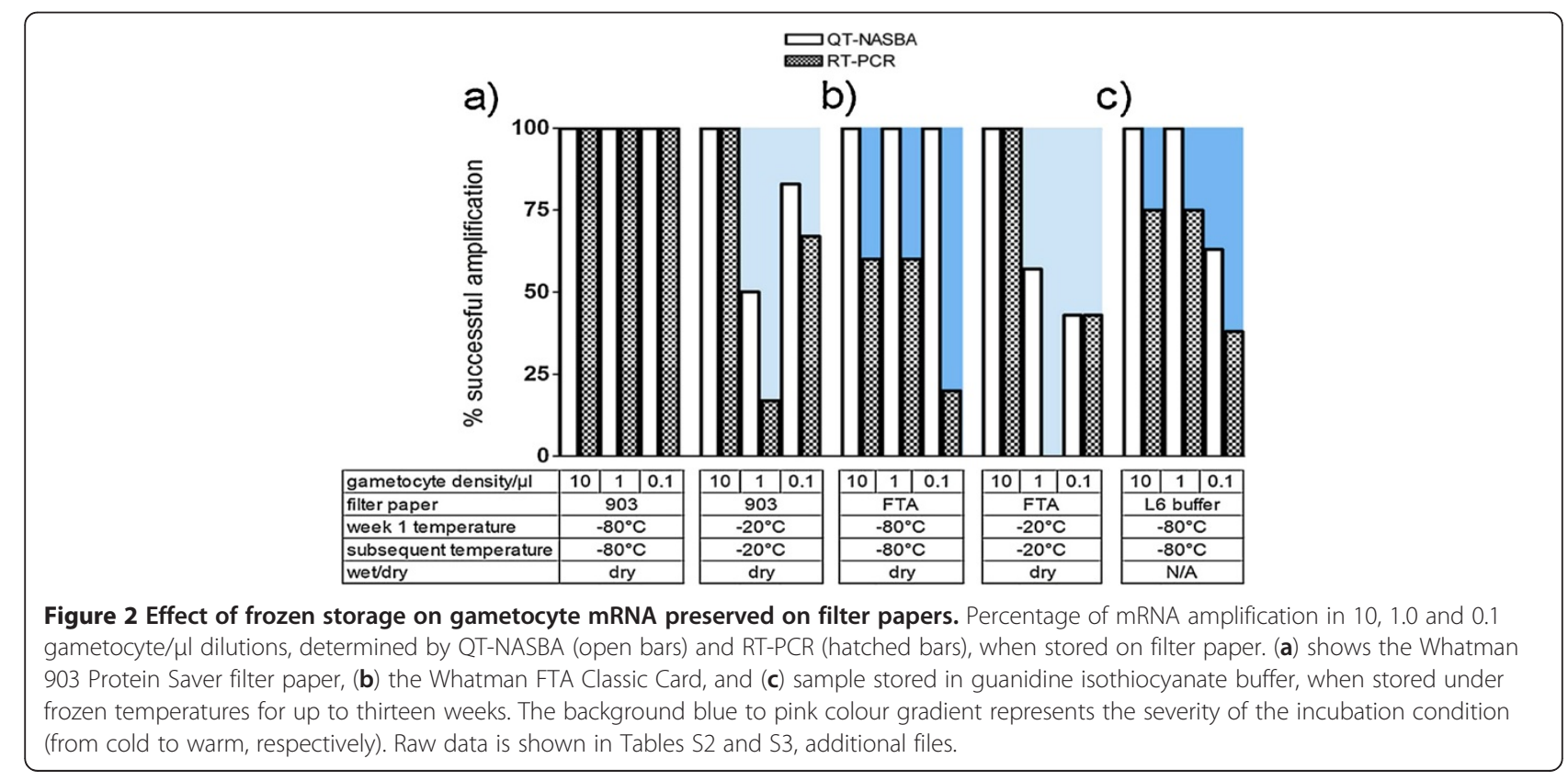


the first condition, $22^{\circ} \mathrm{C}$ for one week followed by $-20^{\circ} \mathrm{C}$ for the next 12 weeks, there was no reduction in the proportion of successfully amplified samples from 903 Protein Saver Card by QT-NASBA (regression analysis adjusting for gametocyte concentration, $\mathrm{p}=0.87$ ). However, there was a clear reduction in the proportion of successfully amplified samples from FTA Classic Cards by QT-NASBA (regression analysis adjusting for gametocyte concentration, $\mathrm{p}=0.049$ ). Comparisons between humid and dry conditions for these storage temperatures gave similar results when RT-PCR was used for gametocyte detection from 903 Protein Saver Cards (regression analysis adjusting for gametocyte concentration, $\mathrm{p}=1.00$ ) or FTA Classic Cards (regression analysis adjusting for gametocyte concentration, $\mathrm{p}=0.009$ ).

When stored at $35^{\circ} \mathrm{C}$, there was a clear reduction in the proportion of successfully amplified samples from 903 Protein Saver Card by QT-NASBA (regression analysis

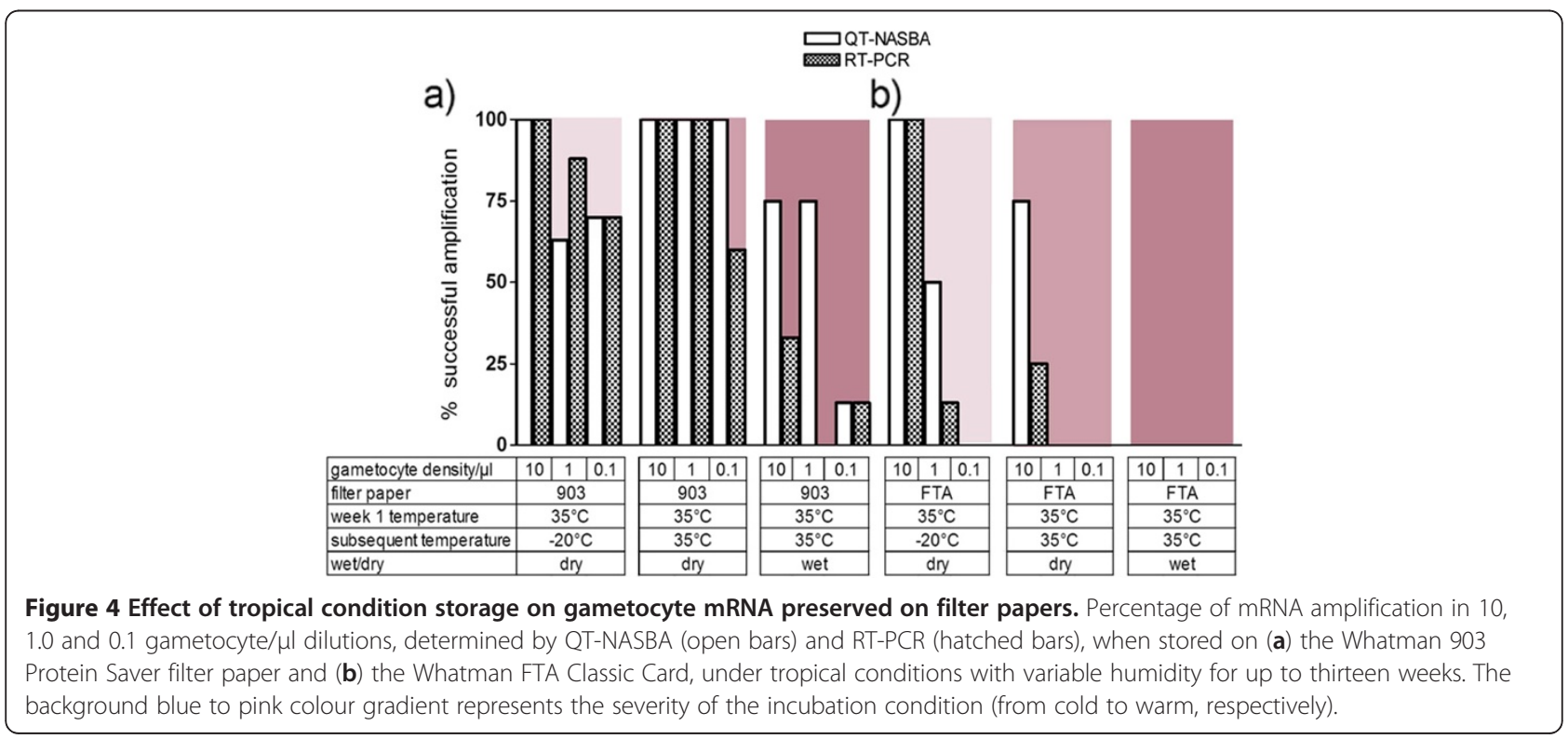




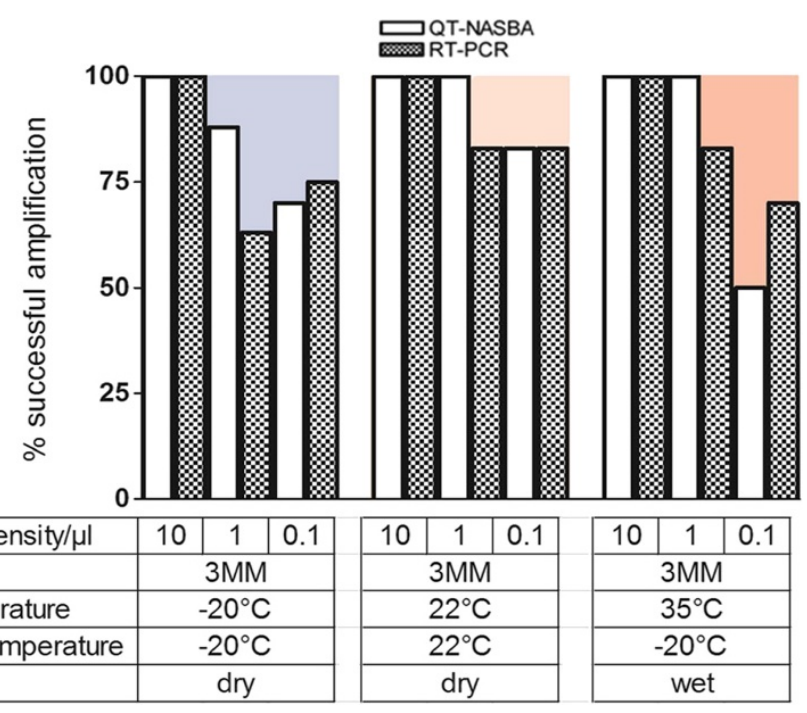

Figure 5 Performance of Whatman $3 \mathrm{MM}$ as a storage media for gametocyte mRNA. Percentage of mRNA amplification in $10,1.0$ and 0.1 gametocyte/ $\mu$ l dilutions, determined by QT-NASBA (open bars) and RT-PCR (hatched bars), when stored on the Whatman 3MM filter paper, incubated under different conditions for up to thirteen weeks. The background blue to pink colour gradient represents the severity of the incubation condition (from cold to warm, respectively).

adjusting for gametocyte concentration, $\mathrm{p}<0.001)$. For FTA Classic Cards, too few samples gave successful amplification for statistical analysis; none of the samples stored under wet conditions at $35^{\circ} \mathrm{C}$ were successfully detected. Comparisons between humid and dry conditions for these storage temperatures gave similar results when RT-PCR was used for gametocyte detection.

Detection of gametocytes from Whatman $3 M M$ filter papers Whatman $3 \mathrm{MM}$ papers were not expected to be a suitable media for mRNA storage, so were incubated under fewer conditions (Figure 5, Tables S2 and S3, additional files). These samples were tested under three conditions: at $-20^{\circ} \mathrm{C}$ for thirteen weeks, at $22^{\circ} \mathrm{C}$ for thirteen weeks and at $35^{\circ} \mathrm{C}$ for one week followed by $-20^{\circ} \mathrm{C}$ storage for the next twelve weeks. When continuously stored at $-20^{\circ} \mathrm{C}$, there was no difference between the proportion of successfully detected samples for all gametocyte dilutions by QT-NASBA between 3MM and 903 Protein Saver Cards (regression analysis adjusting for gametocyte concentration $=0.34$ ) or FTA Classic Cards (regression analysis adjusting for gametocyte concentration, $\mathrm{p}=0.10$ ). When stored continuously at $22^{\circ} \mathrm{C}, 3 \mathrm{MM}$ filter papers performed as well as 903 Protein Saver Cards (regression analysis adjusting for gametocyte concentration, $\mathrm{p}=0.95$ ) but better than FTA Classic Cards (regression analysis adjusting for gametocyte concentration, $\mathrm{p}=0.01$ ). When stored at $35^{\circ} \mathrm{C}$ for one week followed by $-20^{\circ} \mathrm{C}$ for the next twelve weeks, 3MM filter papers performed as well as 903 Protein Saver Cards (regression analysis adjusting for gametocyte concentration, $\mathrm{p}=0.75$ ) but better than
FTA Classic Cards (regression analysis adjusting for gametocyte concentration, $\mathrm{p}=0.01$ ). When RT-PCR was used, similar results were obtained.

\section{Discussion}

This study was designed to investigate optimal collection and storage conditions to enable reliable detection of $P$. falciparum gametocyte densities found in natural infections. Filter papers were found to be a suitable media for Pfs25 mRNA detection from low gametocyte concentrations after storage for up to thirteen weeks. Furthermore, it was found that gametocyte Pfs 25 mRNA stored on 903 Protein Saver Cards is remarkably stable at temperatures higher than $-80^{\circ} \mathrm{C}$.

Unlike the general detection of malaria parasites, which is based on amplification of Plasmodium nuclear or mitochondrial DNA, the specific detection of gametocytes depends on mRNA. Reliable sampling for gametocytes currently depends on RNA extraction in the field $[15,19]$ or storage of samples in stabilizing buffer at $-80^{\circ}$ $\mathrm{C}$ in order to protect the integrity of mRNA, which is much more labile than DNA. The main aims of this study were to determine which filter papers were most suitable for storage of gametocyte mRNA in dried whole blood samples, and to explore flexibility of storage conditions and whether less stringent conditions are permissible without affecting estimates of gametocyte prevalence. This study builds upon similar research evaluating RNA detection from filter paper [22] but provides more rigorous testing with a larger number of replicates in diverse incubation conditions including both high and low 
humidity, which is of particular relevance for sampling in the tropics. QT-NASBA reliably detected gametocyte densities of ten or one gametocyte $/ \mu \mathrm{L}$ when immediately stored in RNA-stabilizing buffer at $-80^{\circ} \mathrm{C}$ and was found to be more sensitive than RT-PCR for detecting low gametocyte concentrations. The higher sensitivity of QTNASBA is unlikely to be explained by amplification of ssDNA [34]; but we do consider it plausible that the DNAse digestion step may have negatively influenced the sensitivity of RT-PCR. It is also important to note that we compared QT-NASBA with RT-PCR as it was previously used for Pfs 25 mRNA detection [22,33]; more sensitive quantitative RT-PCR assays may become available that make this assay comparable in sensitivity to QT-NASBA. Under optimal conditions, storage in RNA-stabilizing buffer at $-80^{\circ} \mathrm{C}$, it was observed that not all samples with 0.1 gametocyte/ $\mu$ Lwere detected by QT-NASBA. This may reflect variability in extraction efficiency or RNA amplification (Churcher et al. in preparation) or an inevitable consequence of very low pathogen concentrations and sample volumes (an average of five gametocytes per $50 \mu \mathrm{L}$ blood sample blotted on the paper). The use of an extraction control could address uncertainties on extraction efficiency between samples but was not used in this study or in other studies using Pfs 25 mRNA RT-PCR or NASBA $[5,6,13,15,29,32,35-37]$.

Detection of gametocytes from filter papers stored at $-80^{\circ} \mathrm{C}$ succeeded with a similar, but slightly higher frequency compared to detection of gametocytes from samples stored directly in RNA stabilizing buffer. The unexpected improved detection from filter paper samples has been previously acknowledged in similar studies [34] where it has been suggested the drying step enhances blood cell lysis, leading to a higher probability of detection. It is currently unclear whether this apparent superiority of filter papers over RNA stabilizing buffer is specific to Pfs 25 mRNA and if other gametocyte mRNA targets are less well stored or recovered using filter papers.

The successful detection of gametocytes from filter papers stored at $-80^{\circ} \mathrm{C}$ formed a useful starting point for analyses that aimed to determine the suitability of filter papers for storage under less favourable conditions. No evidence was found that increasing storage temperature resulted in a lower success rates for gametocyte detection from 903 Protein Saver Cards. Contrary to this, gametocyte detection from the FTA Classic Cards was most efficient when stored at $-80^{\circ} \mathrm{C}$, lower when stored at $-20^{\circ} \mathrm{C}$ or $22^{\circ} \mathrm{C}$ and lowest when stored at $35^{\circ} \mathrm{C}$. FTA Classic Cards were also more susceptible to changes in storage temperature with short-term storage at temperatures higher than $-20^{\circ} \mathrm{C}$ resulting in a loss in detectability of gametocytes from these cards. Qualitative gametocyte detection from 903 Protein Saver Cards was not affected by different storage temperatures.
Incomplete drying of filter papers resulted in a loss in efficiency of gametocyte detection. This effect was most apparent at the highest temperature tested $\left(35^{\circ} \mathrm{C}\right)$ and FTA Classic Cards appeared most susceptible to this detrimental effect of moisture on gametocyte detection. This loss in sensitivity could be a result of RNA degradation and/or incomplete sample elution from insufficiently dried filter papers. It has previously been acknowledged that insufficient drying impacts on the sample elution time which is likely to contribute to the loss in detection seen here. On visual inspection following blood spot elution, filter papers stored under humid conditions remained red, suggesting incomplete recovery of the bloodproduct [38]. Exposure to heat and moisture has been suggested to cause damage or denaturation of RNA not only by the formation of nicks in the nucleic acid strands, or by strand hydrolysis, but also by amplifying degradation caused by UV light exposure [39-42]. Removing moisture by overnight drying and inclusion of desiccant not only prevents physical destruction of the paper, but will also slow RNA degradation.

The general-purpose $3 \mathrm{MM}$ paper permitted detectable RNA recovery as often as the 903 Protein Saver Card and more often than the FTA Classic Card under all conditions. As this filter paper has no specific sample preservation properties and is generally used for DNA and serological sample collection, it was not expected to perform as well as it did. Previous success has been reported for viral RNA storage on the 3MM filter paper, with transcripts being detected after twelve weeks of storage at $32^{\circ} \mathrm{C}$, without a loss in sensitivity [43]. Studies conducting RT-PCR from measles virus RNA stored on the 3MM filter paper have shown successful amplification following twenty-five weeks of storage at room temperature, but a loss in sensitivity with increasing temperature, and detection for just one week post storage for papers incubated at $37^{\circ} \mathrm{C}$ in humid conditions, due to fungal growth [44]. These results are promising, and use of $3 \mathrm{MM}$ is particularly appealing due to its low cost and common use as a substrate for DNA collection $[23,45]$. A recent publication provided evidence that this paper is indeed suitable for Pfs25 mRNA storage [34]. When this publication was in preparation, Pritsch et al. published similar research showing the suitability of 3MM for Pfs 25 mRNA storage for low density gametocytes [34]. Results are in broad agreement: 3MM paper is suitable for Pfs 25 mRNA storage, higher storage temperatures may lead to a lower sensitivity of gametocyte detection, and filter paper Pfs 25 mRNA collection may lead to higher RNA yield than RNA extraction from whole blood samples. The manuscript by Pritsch provides additional details on the stability and quantification of Pfs 25 mRNA; the current manuscript has limitations in the sense that RNA yield from filter papers was not 
determined. The analyses were restricted to gametocyte prevalence and some RNA degradation may therefore have remained undetected. However, the current manuscript extends previous reports on the use of filter paper for RNA storage by the concurrent examination of the sensitivity of RT-PCR, by showing a side-by-side comparison of three filter papers and by examining the effects of a large range of storage conditions including a combination of high temperature and high humidity, which is particularly relevant for field sample collection.

In addition to Pfs 25 mRNA stability and recovery, the cost and operational ease are important considerations when choosing a methodology. The filter papers used in this study differ substantially in cost from USD \$2 for 100 papers for the 3MM, \$133 for 100903 Protein Saver Cards, to approximately $\$ 400$ for 100 of the FTA classic cards, in 2011. Whilst the extraction methods performed equally well in the small comparison conducted, the guanidine-based extraction is more affordable at $\$ 1.2$ per reaction and is more amenable to large-scale extraction. The Qiagen protocol, complete with Qiashredder homogenization and column DNA digest, is more expensive at $\$ 4.5$ per extraction. The individual expense of molecular detection is $\$ 7$ per reaction for QT-NASBA, but amounts to $\sim \$ 14$ for RT-PCR as it requires a DNA digest and a DNA control per sample, to exclude the possibility of DNA contamination. The combination of 903 Protein Saver Cards (which allows a minimum of five spots per card), guanidine extraction and QT-NASBA detection gives a total cost of $\$ 8.5$ per sample. The cheapest combination of methods is the $3 \mathrm{MM}$ paper, guanidinebased extraction and QT-NASBA for detection, which would amount to approximately $\$ 8.22$ per sample.

\section{Conclusions}

In summary, these findings indicate that filter paper cards can be used for collection and storage of Psf25 mRNA for detecting low gametocyte concentrations. The 903 Protein Saver Card and 3MM filter papers are both recommended as they appear particularly promising in this respect and appear to be robust storage media under temperatures higher than those conventionally used for RNA storage. Thorough drying of papers was more important for successful gametocyte detection than the temperature under which samples were stored.

\section{Additional files}

Additional file 1: Table S1. Primer sequences for quantitative nucleic acid sequence based amplification (QT-NASBA) and reverse transcription polymerase chain reaction (RT-PCR).

Additional file 2: Table S2. Detection by RT-PCR of low-density gametocytes stored on filter papers under a range of incubation conditions. Description of data: Data is represented as percent detection, and number of successes/number of tests, for gametocytes stored on Whatman 903 Protein Saver, the Whatman FTA Classic Card and the Whatman $3 \mathrm{MM}$ filter paper for five weeks (top value) and 13 weeks (bottom value). All negative controls were negative (data not shown), NT represents a condition that was not tested.

Additional file 3: Table S3. Detection by QT-NASBA of low-density gametocytes stored on filter papers under a range of incubation conditions. Description of data: Data is represented as percent detection, and number of successes/number of tests, for gametocytes stored on Whatman 903 Protein Saver, the Whatman FTA Classic Card and the Whatman $3 \mathrm{MM}$ filter paper for five weeks (top value) and 13 weeks (bottom value). All negative controls were negative (data not shown), NT represents a condition that was not tested.

\section{Competing interests}

The authors declare that they have no competing interests.

\section{Authors' contributions}

$\mathrm{SJ}, \mathrm{TB}, \mathrm{CD}, \mathrm{CH}$ and $\mathrm{RH}$ designed the experiments, RS contributed reagents for the study, MVB cultured the parasites and SJ, TA, KT and CH set up the study. SJ extracted the RNA, performed the RT-PCR and QT-NASBA and CS provided RT-PCR primers and contributed to RT-PCR protocol design. SJ, TB and CD interpreted the data, SJ, TB and PC performed the statistical analysis and SJ and TB wrote the manuscript. CD and CS revised the manuscript. All authors read and approved the final manuscript.

\section{Acknowledgements}

Filter papers were kindly provided by GE Healthcare Bio-Sciences Corp. This study was funded by the European FP7 project REDMAL (\#242079). The authors thank Dr Godfree Mlambo at the Parasite Core Facility at Johns Hopkins School of Public Health, USA, Dr Tamaki Kobayash from the Department of Epidemiology at Johns Hopkins School of Public Health, USA, Professor Srinivasan Villuppanoor of Indian Immunologicals Limited, Hyderabad, India, and Gillian Stresman in the Department of Immunology and Infection at the London School of Hygiene and Tropical Medicine, UK for sharing their RNA extraction and RT-PCR protocols and providing advice. The authors would also like to thank Amrish Baidjoe from the Department of Medical Microbiology at Radboud University Nijmegen Medical Centre, The Netherlands, for help with QT-NASBA.

Received: 16 May 2012 Accepted: 2 August 2012

Published: 8 August 2012

\section{References}

1. malERA Consultative Group on Vaccines: A research agenda for malaria eradication: vaccines. PLoS Med 2011, 8:e1000398.

2. malERA Consultative Group on Vaccines: A research agenda for malaria eradication: drugs. PLoS Med 2011, 8:e1000402.

3. World Health Organization: Malaria elimination: a field manual for low and moderate endemic countries. Geneva: WHO technical report; 2007.

4. O'Meara WP, Mangeni JN, Steketee R, Greenwood B: Changes in the burden of malaria in sub-Saharan Africa. Lancet Infect Dis 2010, 10:545-555.

5. Ouedraogo AL, Bousema T, Schneider P, de Vlas SJ, Ilboudo-Sanogo E, Cuzin-Ouattara N, Nebie I, Roeffen W, Verhave JP, Luty AJ, Sauerwein R: Substantial contribution of submicroscopical Plasmodium falciparum gametocyte carriage to the infectious reservoir in an area of seasonal transmission. PLoS One 2009, 4:e8410.

6. Schneider P, Bousema JT, Gouagna LC, Otieno S, Vand V, Omar SA, Sauerwein RW: Submicroscopic Plasmodium falciparum gametocyte densities frequently result in mosquito infection. Am J Trop Med Hyg 2007, 76:470-474.

7. Pradel G: Proteins of the malaria parasite sexual stages: expression, function and potential for transmission blocking strategies. Parasitology 2007, 134:1911-1929.

8. Carter R, Gwadz RW: Infectiousness and gamete immunization in Malaria In Research in Malaria. Volume 3. Edited by KJ P.: Academic Press; 1980:263-298.

9. Sauerwein RW: Malaria transmission-blocking vaccines: the bonus of effective malaria control. Microbes Infect 2007, 9:792-795. 
10. Shekalaghe S, Drakeley C, Gosling R, Ndaro A, van Meegeren M, Enevold A, Alifrangis M, Mosha F, Sauerwein R, Bousema T: Primaquine clears dubmicroscopic Plasmodium falciparum gametocytes that persist after treatment with sulphadoxine-pyrimethamine and artesunate. PLOSONE 2007, 2:e1023.

11. Nassir E, Abdel-Muhsin AM, Suliaman S, Kenyon F, Kheir A, Geha H, Ferguson HM, Walliker D, Babiker HA: Impact of genetic complexity on longevity and gametocytogenesis of Plasmodium falciparum during the dry and transmission-free season of eastern Sudan. Int J Parasitol 2005, 35:49-55.

12. Nwakanma $D$, Kheir $A$, Sowa $M$, Dunyo $S$, Jawara $M$, Pinder M, Milligan $P$, Walliker D, Babiker HA: High gametocyte complexity and mosquito infectivity of Plasmodium falciparum in the Gambia. Int J Parasitol 2008, 38:219-227.

13. Ouedraogo AL, Schneider P, de Kruijf M, Nebie I, Verhave JP, Cuzin-Ouattara $\mathrm{N}$, Sauerwein RW: Age-dependent distribution of Plasmodium falciparum gametocytes quantified by Pfs 25 real-time QT-NASBA in a crosssectional study in Burkina Faso. Am J Trop Med Hyg 2007, 76:626-630.

14. Bousema JT, Schneider P, Gouagna LC, Drakeley CJ, Tostmann A, Houben R, Githure II, Ord R, Sutherland CJ, Omar SA, Sauerwein RW: Moderate Effect of Artemisinin-Based Combination Therapy on Transmission of Plasmodium falciparum. JinfectDis 2006, 193:1151-1159.

15. Schneider P, Bousema T, Omar S, Gouagna L, Sawa P, Schallig H, Sauerwein R: (Sub)microscopic Plasmodium falciparum gametocytaemia in Kenyan children after treatment with sulphadoxine-pyrimethamine monotherapy or in combination with artesunate. Int J Parasitol 2006 36:403-408.

16. Abdel-Wahab A, Abdel-Muhsin AM, Ali E, Suleiman S, Ahmed S, Walliker D, Babiker HA: Dynamics of gametocytes among Plasmodium falciparum clones in natural infections in an area of highly seasonal transmission. $J$ Infect Dis 2002, 185:1838-1842.

17. Paganotti GM, Palladino C, Modiano D, Sirima BS, Raberg L, Diarra A, Konate A, Coluzzi M, Walliker D, Babiker HA: Genetic complexity and gametocyte production of Plasmodium falciparum in Fulani and Mossi communities in Burkina Faso. Parasitology 2006, 132:607-614.

18. Drakeley C, Sutherland C, Bousema JT, Sauerwein RW, Targett GA: The epidemiology of Plasmodium falciparum gametocytes: weapons of mass dispersion. Trends Parasitol 2006, 22:424-430.

19. Sutherland CJ, Alloueche A, McRobert L, Ord R, Leggat J, Snounou G, Pinder M, Targett GA: Genetic complexity of Plasmodium falciparum gametocytes isolated from the peripheral blood of treated Gambian children. Am J Trop Med Hyg 2002, 66:700-705.

20. Karl S, David M, Moore L, Grimberg BT, Michon P, Mueller I, Zborowski M, Zimmerman PA: Enhanced detection of gametocytes by magnetic deposition microscopy predicts higher potential for Plasmodium falciparum transmission. Malar J 2008, 7:66.

21. Bauer M, Polzin S, Patzelt D: Quantification of RNA degradation by semi-quantitative duplex and competitive RT-PCR: a possible indicator of the age of bloodstains? Forensic Sci Int 2003, 138:94-103.

22. Mlambo G, Vasquez $Y$, LeBlanc R, Sullivan D, Kumar N: A filter paper method for the detection of Plasmodium falciparum gametocytes by reverse transcription polymerase chain reaction. Am J Trop Med Hyg 2008, 78:114-116.

23. Corran PH, Cook J, Lynch C, Leendertse H, Manjurano A, Griffin J, Cox J, Abeku T, Bousema T, Ghani AC, Drakeley C, Riley E: Dried blood spots as a source of anti-malarial antibodies for epidemiological studies. Malar J 2008, 7:195

24. Taylor BJ, Martin KA, Arango E, Agudelo OM, Maestre A, Yanow SK Real-time PCR detection of Plasmodium directly from whole blood and filter paper samples. Malar J 2011, 10:244.

25. Ponnudurai $T$, Lensen $A H$, Meis JF, Meuwissen JH: Synchronization of Plasmodium falciparum gametocytes using an automated suspension culture system. Parasitology 1986, 93(Pt 2):263-274.

26. Ponnudurai $\mathrm{T}$, Lensen $\mathrm{AH}$, Leeuwenberg $\mathrm{AD}$, Meuwissen $\mathrm{JH}$ : Cultivation of fertile Plasmodium falciparum gametocytes in semi-automated systems. 1. Static cultures. Trans R Soc Trop Med Hyg 1982, 76:812-818.

27. Bousema T, Drakeley C: Epidemiology and infectivity of Plasmodium falciparum and Plasmodium vivax gametocytes in relation to malaria control and elimination. Clin Microbiol Rev 2011, 24:377-410.

28. Babiker HA, Schneider P, Reece SE: Gametocytes: insights gained during a decade of molecular monitoring. Trends Parasitol 2008, 24:525-530.
29. Mens PF, Schoone GJ, Kager PA, Schallig HD: Detection and identification of human Plasmodium species with real-time quantitative nucleic acid sequence-based amplification. Malar J 2006, 5:80.

30. GE Healthcare UK Limited: Whatman FTA ${ }^{T M}$ nucleic acid collection, storage and purification. Buckinghamshire, UK:; 2009. technical report 51641

31. Boom R, Sol CJ, Salimans MM, Jansen CL, Wertheim-van Di PM, Van der NJ: Rapid and simple method for purification of nucleic acids. J Clin Microbiol 1990, 28:495-503.

32. Schneider P, Schoone G, Schallig H, Verhage D, Telgt D, Eling W, Sauerwein R: Quantification of Plasmodium falciparum gametocytes in differential stages of development by quantitative nucleic acid sequence-based amplification. Mol Biochem Parasitol 2004, 137:35-41.

33. Stresman GH, Kamanga A, Moono P, Hamapumbu H, Mharakurwa S, Kobayashi T, Moss WJ, Shiff C: A method of active case detection to target reservoirs of asymptomatic malaria and gametocyte carriers in a rural area in Southern Province Zambia. Malar J 2010, 9:265.

34. Pritsch M, Wieser A, Soederstroem V, Poluda D, Eshetu T, Hoelscher M, Schubert S, Shock J, Loescher T, Berens-Riha N: Stability of gametocyte-specific Pfs25-mRNA in dried blood spots on filter paper subjected to different storage conditions. Malar J 2012, 11:138.

35. Mens PF, Sawa P, van Amsterdam SM, Versteeg I, Omar SA, Schallig HD, Kager PA: A randomized trial to monitor the efficacy and effectiveness by QT-NASBA of artemether-lumefantrine versus dihydroartemisininpiperaquine for treatment and transmission control of uncomplicated Plasmodium falciparum malaria in western Kenya. Malar J 2008, 7:237.

36. Mens P, Spieker N, Omar S, Heijnen M, Schallig H, Kager PA: Is molecular biology the best alternative for diagnosis of malaria to microscopy? A comparison between microscopy, antigen detection and molecular tests in rural Kenya and urban Tanzania. Trop Med Int Health 2007, 12:238-244.

37. Schneider P, Wolters L, Schoone G, Schallig H, Sillekens P, Hermsen R, Sauerwein $R$ : Real-time nucleic acid sequence-based amplification is more convenient than real-time PCR for quantification of Plasmodium falciparum. J Clin Microbiol 2005, 43:402-405.

38. Mei JV, Alexander JR, Adam BW, Hannon WH: Use of filter paper for the collection and analysis of human whole blood specimens. J Nutrition 2001, 131:1631s-1636s.

39. Kansagara AG, McMahon HE, Hogan ME: Dry-state, room-temperature storage of DNA and RNA. Nature Meth 2008, 5:850.

40. Rogers $C D$, Burgoyne $L A$ : Reverse transcription of an RNA genome from databasing paper (FTA(R)). Biotechnol Appl Biochem 2000, 31(Pt 3):219-224.

41. Dobbs LJ, Madigan MN, Carter AB, Earls L: Use of FTA gene guard filter paper for the storage and transportation of tumor cells for molecular testing. Arch Pathol Lab Med 2002, 126:56-63.

42. Moscoso H, Raybon EO, Thayer SG, Hofacre CL: Molecular detection and serotyping of infectious bronchitis virus from FTA filter paper. Avian Dis 2005, 49:24-29.

43. Michaud V, Gil P, Kwiatek O, Prome S, Dixon L, Romero L, Le Potier MF, Arias M, Couacy-Hymann E, Roger F, Libeau G, Albina E: Long-term storage at tropical temperature of dried-blood filter papers for detection and genotyping of RNA and DNA viruses by direct PCR. J Virol Methods 2007 146:257-265.

44. De Swart RL, Nur $Y$, Abdallah A, Kruining $H$, El Mubarak HS, Ibrahim SA, Van Den Hoogen B, Groen J, Osterhaus AD: Combination of reverse transcriptase PCR analysis and immunoglobulin $\mathrm{M}$ detection on filter paper blood samples allows diagnostic and epidemiological studies of measles. J Clin Microbiol 2001, 39:270-273.

45. Cook J, Reid H, lavro J, Kuwahata M, Taleo G, Clements A, McCarthy J, Vallely A, Drakeley C: Using serological measures to monitor changes in malaria transmission in Vanuatu. Malar J 2010, 9:169.

doi:10.1186/1475-2875-11-266

Cite this article as: Jones et al:: Filter paper collection of Plasmodium falciparum mRNA for detecting low-density gametocytes. Malaria Journal 2012 11:266 